\section{Aortoenteric Fistula: A Difficult Situation Requiring Multiple Treatment Options}

Sir,

Aortoenteric fistula (AEF) is a communication between the aorta and an adjacent bowel loop. ${ }^{1}$ It can be primary or secondary. Secondary AEF is a rare complication after aortic reconstruction with prosthetic grafts. Most common involved bowel segment is the duodenum. ${ }^{2}$ If left untreated, AEF is fatal due to ongoing bleeding and sepsis. 3,4

Between January 2013 and December 2014, we had managed five patients with AEF. Most of them were males (4:1) with mean age of 48.5 years (range 35 - 65 years). Major comorbidities were hypertension. Most of them had secondary AEF (4:1). Three patients had aortic repair for aneurysmal disease with prosthetic grafts. One patient had aortic reconstruction for severe stenosis. Mean duration between aortic surgery and presentation of secondary AEF was 4.5 years (0.3-15 years). Three patients presented with hematemesis, while two with sepsis. All AEF were diagnosed on computed tomography. All patients with secondary AEF were managed with surgery. Revascularisation was achieved by either axillo-bifemoral bypass graft, in situ native grafts using both femoral veins, or by in situ antibiotic soaked prosthetic grafts, one patient each. In one patient, only debridement of infected retroperitoneal tissue was performed while the graft was left intact. The patient with primary AEF was managed by placing a covered stent across the fistulous tract. In patients with secondary $A E F$, all fistulous defects in the duodenum were repaired primarily. The omentum was brought through a window created in the mesentery of the transverse colon and placed between the duodenum and the graft. Feeding jejunostomies were also created in all patients. One patient died in the immediate postoperative period. One patient had recurrent urinary tract infections and prolong ICU stay. All patients were followed for an average of 24 months and had smooth recovery.
The operative mortality rate in this small series is $20 \%$, which is on the lower range as described in literature (range 13\%-57\%). $3-5$

\section{CONFLICT OF INTEREST:}

Authors declared no conflict of interest.

\section{AUTHORS' CONTRIBUTION:}

ZUR: Study concept, data collection, data analysis, investigation, writing, critical review and revision, and final approval of the article.

ZS: Study concept, critical review and revision, and final approval of the article.

\section{REFERENCES}

1. Chung J. Management of aortoenteric fistula. Adv Surg 2018; 52:155-77.

2. Lee W, Jung CM, Cho EH, Ryu DR, Choi D, Kim J. Primary aortoenteric fistula to the sigmoid colon in association with intra-abdominal abscess. Korean J Gastroenterol 2014; 63: 239-43.

3. Bíró G, Szabó G, Fehérvári M, Münch Z, Szeberin Z, Acsády G. Late outcomes following open surgical management of secondary aortoenteric fistula. Langerbecks Arch Surg 2011; 396:1221-9.

4. Guner A, Mentese U, Kece C, Kucuktulu U. A rare and forgotten diagnosis of gastrointestinal bleeding: Primary aortoduodenal fistula. BMJ Case Rep 2013; 2013008712.

5. Schoell T, Manceau G, Chiche L, Gaudric J, Gibert H, Tresallet C, et al. Surgery for secondary aortoenteric fistula or erosion (SAEFE) complicating aortic graft replacement: A retrospective analysis of 32 patients with particular focus on digestive management. World J Surg 2015; 39:283-91.

Zia Ur Rehman and Ziad Sophie

Department of Surgery, The Aga Khan University Hospital, Karachi, Pakistan

Correspondence to: Dr. Zia Ur Rehman, Department of Surgery, The Aga Khan University Hospital, Karachi, Pakistan E-mail: ziaur.rehman@aku.edu

Received: December 05, 2018; Revised: March 18, 2019; Accepted: March 18, 2019

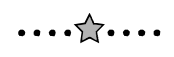

